\title{
MAKING DRY NOODLES MADE FROM CASSAVA FLOUR (MANIHOT ESCULENTA CRANTZ) AND CASSAVA STARCH
}

\author{
Adnan Engelen ${ }^{1)}$, Rahmat A Rahman'), Arif Murtaqi Akhmad Mutsyahidan ${ }^{3)}$ \\ 1,2,3) Department of Agricultural Product Technology, Polytechnic of Gorontalo, \\ E-mail : adnanengelen@poligon.ac.id ${ }^{1)}$ \\ Indonesia
}

\section{ABSTRACT}

This study aimed to determine the best formulation of dry noodle making from cassava flour and cassava starch and to see the physical and chemical properties of dry noodles. This study used a completely randomized design (CRD) and LSD test if there was a significant effect. Tests carried out included organoleptic tests, air content analysis, ash content analysis, color analysis, and texture analysis. The results showed that the best formulation of dry noodles consisted of a composition of 120 grams of cassava flour and 80 grams of cassava starch (M1) with a moisture content value of $9.81 \%$, and ash content analysis of $8,7 \%$, color analysis of $22,1 \%$ and texture analysis. $117,27 \%$ and had a savory taste, the aroma was not too strong, and the color was a bit pale yellow.

Keywords: dry noodle, cassava flour, cassava starch

\section{INTRODUCTION}

Dry noodles are dried fresh noodles until the water content is ranged of 8-10\%. Usually the drying process is achieved by drying it out in the sun or by an oven. Dry noodles are low in water, have a relatively long shelf life and are easy to handle ( $\mathrm{Li}$, et al. 2017).

The main ingredient widely on the market for making noodles is wheat flour. Noodle goods are not originally manufactured in Indonesia, so they must also be imported. Wheat flour has a defect, namely that it is difficult to digest the gluten in the flour so that it prevents the metabolism of the body, produces allergens (allergen) for people with gluten sensitivity. Therefore, material substitutions are required to reduce reliance on imported materials and the shortages in wheat flour. The type of meal to be replaced with wheat flour should have a similar

\section{RESEARCH METHODS}

\subsection{Place and Time of Research}

This study was carried out in July 2019 at Gorontalo of Polytechnic, Laboratory of Agricultural Product Technology.

\subsection{Material And Methods For Analysis}

The main ingredient used was cassava that originates from the Gorontalo City central market. Other ingredients used to make dry noodles included eggs, water, oil and salt. A drying oven, noodle molds, steamer, analytical scales, porcelain dishes, glass texture analyser, and colorimeter equipment were the instruments used for this study. The drying oven was square, $100 \mathrm{~cm} \times 100 \mathrm{~cm}$ tall. Cassava flour (60 percent, 50, 40 percent) and cassava starch (40 percent, 50 percent, 60 percent) were used to make dry noodles with a total weight of $200 \mathrm{~g}$ mixed with oil, water, eggs, and salt until a dough was quality value, so that the quality of the noodle products produced is not quite different.

Cassava flour has been used in this analysis as a raw material for making noodles. This meal includes temperature amounts of amylose, amylopectin, and gelatinization near the wheat flour. Wheat flour has a 25 percent amylose content, 75 percent amylopectin content, and 52-64 ${ }^{\circ} \mathrm{C}$ gelatinization temperature, while cassava flour has an amylose content of 17 percent, 80 percent amylopectin content, and $52-64{ }^{\circ} \mathrm{C}$ gelatinization temperature (Risti, 2013). Cassava flour is very easy to find in Indonesia apart from the levels of amylose, amylopectin, and temperature of gelatinization that are similar to wheat meal. Cassava flour is less costly than wheat meal. The physical examination was conducted to assess the effect on the water quality, ash content, color analysis, noodle stickiness.

obtained. The dough was then rolled into sheets of noodles, then steamed for 10 minutes, then the sheets were printed using a noodle press. For 2 minutes the noodles which came out of the mold were steamed.

\subsection{Production}

The method of making dry cassava noodles starts with weighing the ingredients, namely cassava flour $(60 \% ; 50 \% ; 40 \%)$ and cassava starch $(40 \%$; $50 \%$; $60 \%$ ) with a total weight of $200 \mathrm{~g}$ and then combined with other ingredients. For example 50 $\mathrm{mL}$ of water, $26 \mathrm{~mL}$ of oil, 2 eggs and 5 grams of salt, then knead to form a doughy dough.

The mixed dough is then flattened into sheets and then steamed for 10 minutes, with the aim of gelatinizing some of the starch (about 70 percent) so that it can serve as a dough binder. The dough can 
not be formed and molded into noodles, if steaming is not finished. This is because cassava's endosperm protein contains a lot of zein (60 percent) that can not form an elastic-cohesive dough mass if only water is applied and kneaded in wheat like gliadin and glutenin (Soraya, 2006).

After the sheet steaming is printed using a noodle printer, it becomes noodle threads, then dried for 2 hours in an oven at $70{ }^{\circ} \mathrm{C}$.

\subsection{Analysis Procedure}

2.4.1. Analysis of The Water Content (Codex Standard 2006)

The plates were heated around 15 minutes at $105^{\circ} \mathrm{C}$, during which the plates were refrigerated for 15 minutes in a desiccator.

The noodles used are 2 grams of dry sago noodles mounted in a porcelain cup known to weigh. The plate containing the sample shall be set in an oven for 4 hours at $105^{\circ} \mathrm{C}$. After that, the plates were refrigerated for 15 minutes in a desiccator and then weighed again. The water content of sago noodles is calculated using the formula below:

Moisture content $(\% \mathrm{bb})=\frac{(x-y)}{(x-a)} \times 100$.

Note.

$\mathrm{x}=$ weight of plates and samples before drying $(\mathrm{g})$

$\mathrm{y}=$ plate and sample weight after drying $(\mathrm{g})$

$\mathrm{a}=$ weight of empty cup $(\mathrm{g})$

\subsubsection{Analyzing of The Ash Content} (Andarwulan et al, 2011)

The empty slabs are measured like a gram. 5 grams of the test material are then placed into a cup, weighed and registered as weight $b$ grams. Ashes are performed in 2 phases, namely heating at $300{ }^{\circ} \mathrm{C}$ to preserve the volatile and fat content before the acid content is lost. Heating up until the acid runs out more, steadily heating up to $600{ }^{\circ} \mathrm{C}$ at a rate such that abrupt temperature changes do not cause the cup to burst. Can measure the ash content in the sample using the formula:

$$
\% \text { Ash } \frac{\mathrm{W} 2-\mathrm{W} 1}{W 1-W 0} X 100 \text {. }
$$

Note:

$\mathrm{W} 0=$ Weight of empty cup (g)

$\mathrm{W} 1=$ Weight of plate + sample before ashing $(\mathrm{g})$

$\mathrm{W} 2=$ Weight of plate + sample after ashing $(\mathrm{g})$
2.4.3. Color Analysis (Andarwulan et al, 2011)

Color measurement using the AMT-507 handheld colorimeter. Measurements generate values of $\mathrm{L}, \mathrm{C}$, and $\mathrm{H}, \mathrm{L}$ denote parameters of brightness (achromatic colour, 0: black to 100: white), $\mathrm{C}$ denotes the level of color based on its sharpness, which determines the color of an object that tends to be pure or that tends to be dirty. (gray). Saturation follows a percentage ranging from 0 percent to 100 percent as the sharpest colour, Hue is a color attribute dependent on the light reflected by the material, it is seen from its size following levels 0 to 359 in terms of colour. For eg, at level 0 is Red, for Green, 60 is Yellow at 120 levels, while those at 180 are cyan (turquoise). For level 240 is a color Blue, and 300 is a color Magenta.

\subsubsection{Measurement of Texture Profile Analysis (TPA) (AACC 66-50.01.1999)}

Using Texture Analyser (HD-Plus) tool to analyze the texture. The probe used has a diameter of $35 \mathrm{~mm}$. The distance from the probes is $20 \mathrm{~mm}$. The measuring method is for a rehydrated sample with a length exceeding the diameter of the probe to be positioned on the anvil and then pressed by the probe. The effect is a curve that shows the relation between the force of deformation and the time. The hardness value is given by the absolute (+) peak, which is the maximum power, and the absolute-) (peak indicates the stickiness value. The unit for each of these parameters is gram force (gf). The elasticity is obtained from the ratio of unit gram second (gs) between the two compressive areas.

\section{RESULTS AND DISCUSSION}

\subsection{Organoleptic Test}

\subsubsection{Taste}

The taste buds can discern four main flavours, namely salty, sour, sweet, bitter, and umami according to Melis and Barbarossa (2017). There are several factors influencing the taste, including chemical compounds and their interactions with other elements. The results are defined in Figure 1 based on the organoleptic test for the taste of dry noodles, cassava flour and starch substitution. 


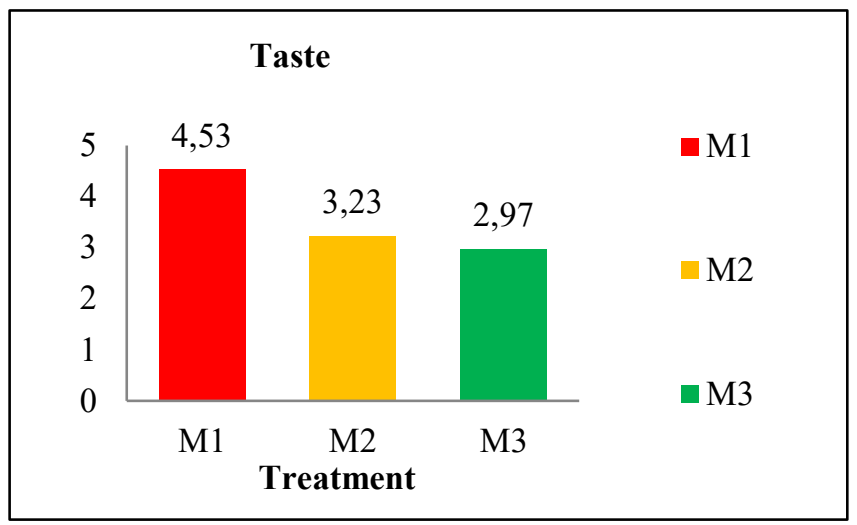

Figure 1. Composition of preferred amount for dry noodle taste

The findings of the organoleptic test on the taste of dry noodles showed that the rate of approval ranged from 2.97-4.53 or in the degree of dislike to neutral. M1 dry noodles (120 grams of cassava flour: 80 grams of starch) produce a slightly unpleasant taste, M2 (100 grams of cassava flour: 100 grams of starch), and M3 (80 grams of cassava flour: 120 grams of starch), which creates an unpleasant taste. In the M1 test, panelists favored the taste of dry noodles as opposed to other therapies. This is in line with the Milde et al. 2012 research which conducted an acceptance study in which materials containing higher starch were well accepted by consumers.

\subsubsection{Flavor}

The Flavor is an odor induced by chemical stimulation that reflect information derived from multiple sensory afferents, including gustatory, olfactory, and somatosensory fibers. Although flavor perception therefore arises from the central integration of multiple sensory inputs, it is possible to distinguish the different modalities contributing to flavor, especially when attention is drawn to particular sensory characteristics (Stevenson, 2012). The results are defined in Figure 2 based on the organoleptic test for taste of dry noodles, cassava flour, and starch substitution.

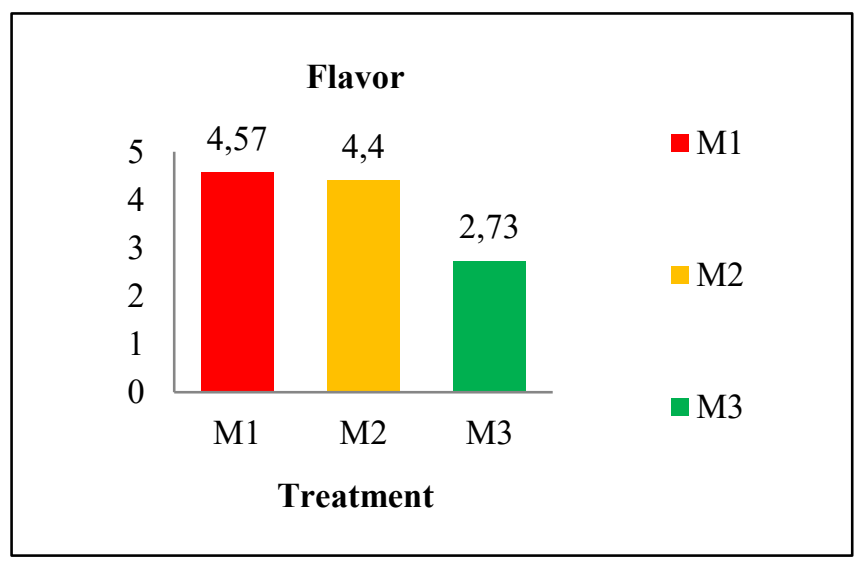

Figure 2. Composition of preferred amount for dry noodle flavor

The results of the organoleptic test on the aroma of dry noodles showed the extent of panelist approval of the aroma parameters in dry noodles replaced with cassava flour and cassava starch showed a value ranging from 2.73-4.57 or to the degree of dislike. M1 dry noodles (120 grams of cassava flour: 80 grams of starch) offer a neutral flavour, a neutral aroma is produced by M2 (100 grams of cassava flour: 100 grams of starch) and by M3 (80 grams of cassava flour: 120 grams of starch).
Similar. In therapy with M1, panelists favored the scent of dry noodles compared with other therapies. This is because the treatment with M1 has a less pungent aroma due to the large amount of starch which causes certain chemical content in cassava starch to modify the aroma of dry noodles if it is used too frequently. This is in line with Castillo (2014) opinion which states that odors, depending on the specific chemical compound and the time of 
touch, cause activation in a particular area of the smell.

\subsubsection{Color}

According to Bello et al (2013), Color is one of the important quality characteristics and major factors affecting sensory perception and consumer acceptance of foods. Besides that, there are other considerations like microbiological characteristics, for example. Compared to other factors the color aspect comes first and is very definitive. The results are shown in Figure 3, based on the organoleptic test on color of dry noodles replaced with cassava flour and cassava starch

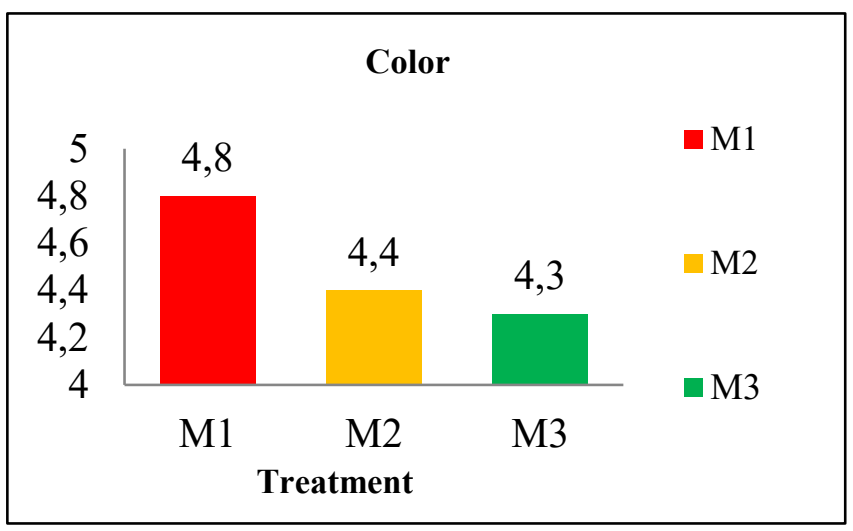

Figure 3. Composition of preferred amount for dry noodle color

The results of the organoleptic test on dry noodle color showed M1 dry noodles (120 grams of cassava flour: 80 grams of starch), M2 (100 grams of cassava flour: 100 grams of starch) and by M3 (80 grams of cassava flour: 120 grams of starch). The level of panelist acceptance of dry noodle color parameters replaced with cassava flour and cassava starch showed a value ranging from 4.3-4.8 or in neutral.. The variations in the color of the starch and flour of the cassava can be due to various processing procedures.

\subsection{Chemical Properties Analysis \\ 3.2.1. Moisture Content}

Water is an essential component of food ingredients, as it can influence the appearance, texture and taste of food. The moisture content of cassava flour and cassava starch produced in dry noodles ranged from 7.35 to 9.81 percent.

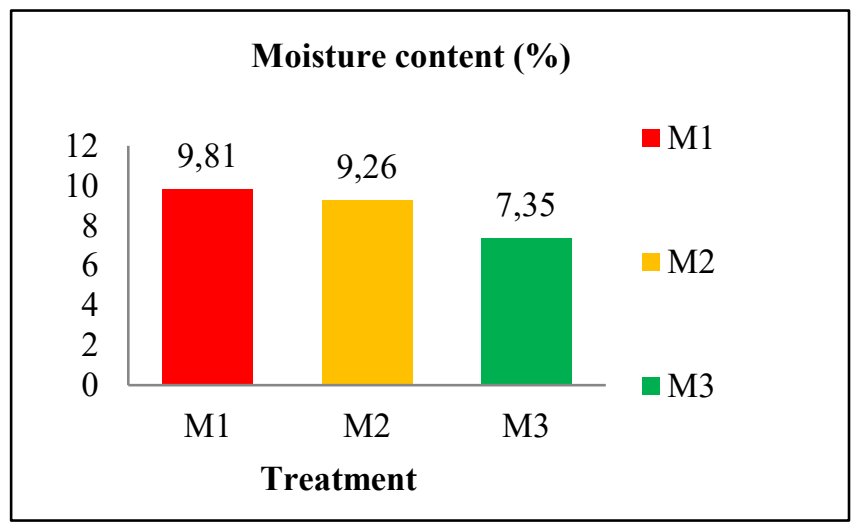

Figure 4. The results of an analysis of the dry noodles' moisture content

The results of the water content analysis showed that M1 dry noodles (120 grams of cassava flour: 80 grams of starch), M2 (100 grams of cassava flour: 100 grams of starch) and by M3 (80 grams of cassava flour: 120 grams of starch). The highest amount of water content was found in the M1 process. This is because the amount of cassava flour used is more than the starch, namely 120 grams of cassava flour and 80 grams of starch. This assertion is based on Ladamay and Yuwono's (2004) opinion that the higher the amount of cassava flour, the greater the water content. Water content is determined by the water content that is chemically attached to food, in cassava flour it has 70 percent 
while in starch it has absolutely no water content because starch consists only of amylose and amylopectin. Dry noodles replacing cassava flour and cassava starch with M1, M2, and M3 can be said to follow SNI (01-2974-1996) requirements because the normal water content of dry noodles is $8-10 \%$

Based on the variance study, Fcount 7.25 has a value greater than Ftable 5.14 (5\%), Ftable 10.92 $(1 \%)$, suggesting that dry noodles with cassava flour and cassava starch substitutions are substantially different at Level 5. Percentage, followed by further LSD testing. Results were listed in table 1.

\begin{tabular}{cc}
\hline Treatment & Average $(\%)$ \\
\hline $\mathrm{M}_{1}$ & $9.26^{\mathrm{ab}}$ \\
$\mathrm{M}_{2}$ & $9.81^{\mathrm{a}}$ \\
$\mathrm{M}_{3}$ & $7.35^{\mathrm{b}}$ \\
\hline
\end{tabular}

Note: Different notes display different effects at level of 5 percent

Comes from the LSD research showed that the effects of treatment with M1 differed significantly from treatment with M2 and M3, the comes of treatment with M2 differed significantly from treatment with M1 and M3, the effects of treatment with M3 were significantly different from treatments with M2 and M1. This is probably due to different drug compositions in the three treatments such that the outcomes of the three treatments varied considerably.

Table 1. The average value of dry noodle moisture content.

\subsubsection{Ash content}

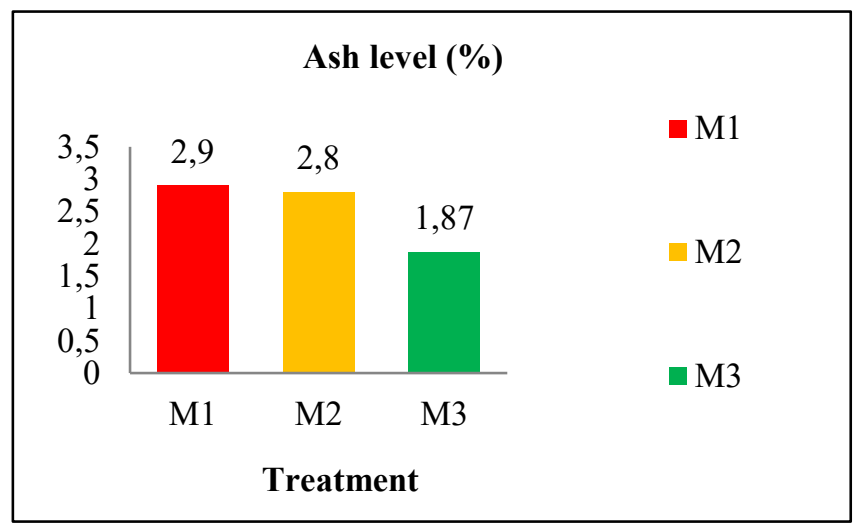

Figure 5. The results of an analysis of the ash content of dry noodles

The results of an analysis of the ash content showed that M1 dry noodles (120 grams of cassava flour: 80 grams of starch), M2 (100 grams of cassava flour: 100 grams of starch) and by M3 (80 grams of cassava flour: 120 grams of starch). The highest amount of ash content was in the treatment with M1. This is because more than the starch is the amount of cassava flour used, namely 120 grams of cassava flour and 80 grams of starch. This statement is based on the opinion (Faza, 2007) that the more cassava flour the ash content will increase due to the $0.2 \%$ ash content of cassava flour.

Based on the variance analysis that Fcount (7.65) is higher than Ftable (5 percent) 5.14 Ftable (1 percent) 10.92 , indicating that dry noodles with substitutions for cassava flour and cassava starch are significantly different at 5 percent, followed by a further LSD test, as described in table 2.
Table 2. The mean value of dry noodle ash content.

\begin{tabular}{cc}
\hline Treatment & Average $(\%)$ \\
\hline $\mathrm{M}_{1}$ & $2.90^{\mathrm{ab}}$ \\
$\mathrm{M}_{2}$ & $2.80^{\mathrm{a}}$ \\
$\mathrm{M}_{3}$ & $1.87^{\mathrm{b}}$ \\
\hline
\end{tabular}

Note: Different notes display different effects at level of 5 percent

Test results showed that M1 treatment outcomes were significantly different from M2 and M3 treatment, M2 treatment was significantly different from M1 and M3 treatment, treatment outcomes M3 was significantly different from M2 and M1 treatment. This was due to the different formulations of materials in the three treatments, therefore the results of the three treatments were significantly different. 


\subsubsection{Color}

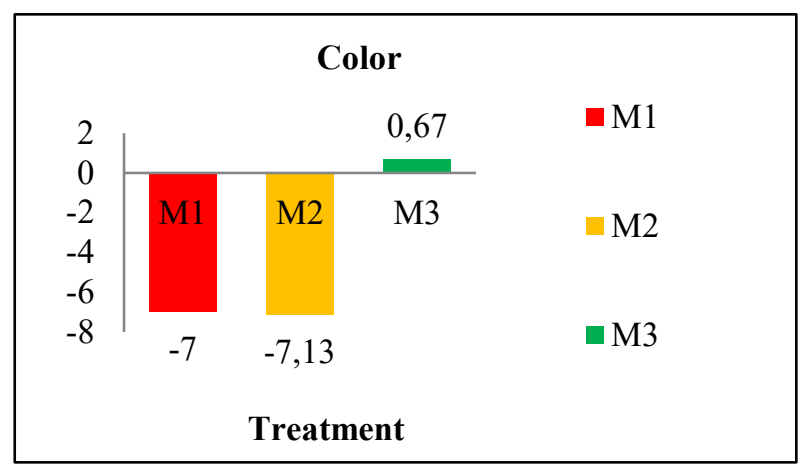

Figure 6. Results of dry noodles color analysis

Figure 6 illustrates M1 dry noodles (120 grams of cassava flour: 80 grams of starch), M2 (100 grams of cassava flour: 100 grams of starch) and by M3 (80 grams of cassava flour: 120 grams of starch), that the color test value of dry cassava noodles and cassava starch obtained 3 spatial co-ordinates, namely $\Delta \mathrm{L}$ the difference between light or dark (plus $(+)=$ light,$\quad$ minus $(-)=$ dark $), \Delta \mathrm{C}$ the difference between lightness and dullness (plus $(+)=$ bright, minus $(-)=$ dull $), \Delta \mathrm{H}$ the difference between hue.

Based on the variance analysis, it shows that the $\Delta \mathrm{L}$ value of the cassava flour and cassava starch combination varies significantly. The value of $\Delta \mathrm{C}$ was significantly different, whereas the value of $\Delta H$ was not significantly different from the value of the produced mi color. Based on the value of the M1 and M2 treatments, it explains that they have a darker color than the treatment with M3. Based on the $\Delta \mathrm{C}$ value of treatment M1, M2 and M3 tended to be dull, the value of $\Delta \mathrm{H}$ treatment M2 was opposite to treatment $\mathrm{M} 1$ and $\mathrm{M} 3$ in $\mathrm{L}^{*} \mathrm{C}^{*} \mathrm{H}$. This illustrates that treatment with $\mathrm{M} 2$ is less yellow than treatment with $\mathrm{M} 1$ and M3. The average in $\mathrm{L}^{*} \mathrm{C}^{*} \mathrm{H}$ can be showed in table 3 .

Table 3. The average $\mathrm{L}^{*} \mathrm{C} * \mathrm{H}$ values

\begin{tabular}{ccccc}
\hline Treatment & $\Delta \mathrm{L}$ & $\Delta \mathrm{C}$ & $\Delta \mathrm{H}$ & $\Delta \mathrm{E}$ \\
\hline $\mathrm{M}_{1}$ & -7.00 & -2.03 & -3.07 & 20.33 \\
$\mathrm{M}_{2}$ & -7.13 & -6.63 & 1.43 & 7.07 \\
$\mathrm{M}_{3}$ & 0.67 & -1.93 & -3.00 & 10.20 \\
\hline
\end{tabular}

\subsubsection{Texture}

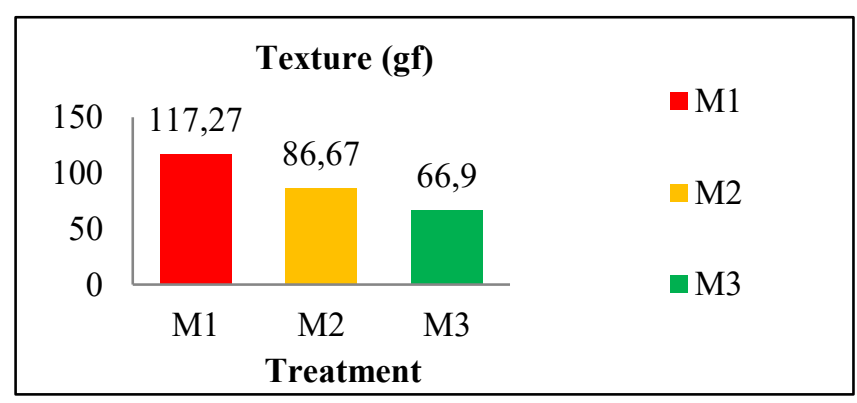

Figure 7. The results of the dry noodle texture analysis

The texture analysis results M1 dry noodles (120 grams of cassava flour: 80 grams of starch), M2 (100 grams of cassava flour: 100 grams of starch) and by M3 ( 80 grams of cassava flour: 120 grams of starch) showed M1 was the highest treatment. This is because the amount of cassava flour used is greater than the starch, i.e. 120 grams of cassava flour and 80 grams of starch, the more amylose it is, the less sticky it will decrease. This is supported by Cornejo-Ramírez et al (2018), who states that the higher the amylose content makes the gel structure stronger and resulting in lower adhesivity.

Based on the variance analysis, that Fcount (7.93) is higher than Ftable (5 percent) 5.14 Ftable (1 percent) 10.92 , indicating that dry noodles with cassava flour and cassava starch substitutions are significantly different at a level of 5 percent, followed by a further LSD test, the results were described in table 4. 
Table 4. The mean value of dry noodle texture.

\begin{tabular}{cc}
\hline Perlakuan & Rata-rata $(\mathrm{gf})$ \\
\hline $\mathrm{M}_{1}$ & $117.7^{\mathrm{a}}$ \\
$\mathrm{M}_{2}$ & $86.7^{\mathrm{b}}$ \\
$\mathrm{M}_{3}$ & $66.90^{\mathrm{c}}$
\end{tabular}

$\overline{\text { Note: Different notes display different effects at level of } 5 \text { percent }}$

The LSD test results show that the results of treatment M1, M2 and M3 are significantly different. This is presumably due to various material formulations in the three treatments so that the results of the three treatments did not differ significantly.

\section{Conclusion}

The conclusion of this analysis is that treatment with M1 is the best organoleptic test results for the three parameters of taste, aroma and color. M1 treatment was the best treatment on the basis of the water content, ash content and texture test results, while $\mathrm{M} 3, \mathrm{M} 2, \mathrm{M} 2$, respectively, was the best color test on the values of delta $\mathrm{L}$, delta $\mathrm{C}$, delta $\mathrm{H}$, delta $\mathrm{E}$.

\section{BIBLIOGRAPHY}

Andarwulan, N., Kusnandar, F., Herawati, D. 2011. Food analysis. Jakarta: Dian Rakyat.

[AACC] American Association of Cereal Chemists. 1999. AACCI method 66-50.01, pasta and noodle cooking quality -firmness. $\mathrm{Di}$ dalam: AACC International Approved Methods of Analysis, Eleventh Edition. St. Paul (USA): AACC International.

[BSN] National Standardization Institute. 1996. Indonesian National Standard, SNI 012974-1996, Dry noodle quality requirements. Jakarta.

Andres-Bello A, V. Barreto-Palacios, SegoviaGarcia P, Mir-Bel J, Martinez-Monzo. 2013. Effect of $\mathrm{pH}$ on color and texture of food product. Food Eng 5:158-170.

Cornejo-Ramírez, Y.I., Martinez-Cruz, O., DelToro-Sanchez,C.L.,Wong-Corral,F.J., Borboa-Flores, J and Cinco-Moroyoqui, F.J. 2018. The structural characteristic of starches and their functional properties. CYTA-Journal of Food 16 (1): 1003-1017.

Castillo M. 2014. The complicated equation of smell, flavor, and taste. AJNR Am J Neuroradiol. 35:1243-45.

Faza, F. 2007. Reduce flour imports with mocaf. http://agrina-online.com.
Ladamay, N.A. dan Yuwono, S.S. 2014. Utilization of local materials in the manufacture of foodbars (study of the ratio of tapioca: mung bean flour and the proportion of CMC). Journal of Food and Agroindustry Vol.2 No1: 67-68.

Li L, Wang N, Ma S, Yang S, Chen X, Ke Y, and Wang X. 2018. Relationship of Moisture Status and quality characteristic of fresh wet noodles prepared from different grade wheat flours from flour milling streams. Journal of Chemistry. 1: 1-8.

Melis M and Barbarossa I.T. 2017. Taste Perceptionof sweet, sour, salty,bitter, and umamiand changes due to L-arginine supplementation, as a function of genetic ability to taste 6-n-Propylthiouracil. Nutrients, 9(541): 1-17.

Milde AL.B, Ramallo L.A, Puppo M.C. 2012. Gluten-free bread based on tapioca starch: Texture and sensory studies. Food Biopress Technol, 5:888-896.

Risti, Y. 2013. The effect of adding eggs on protein, fiber, chewiness level and acceptance of gluten-free noodles made from composite flour. Thesis. S1 Nutrition Science Program, Faculty of Medicine, Diponegoro University. Semarang.

Soraya, A.2006. Process design and formulation of wet corn noodles made from high quality protein maize of the harvested dry yellow "Srikandi" variety. Thesis. Faculty of Agricultural Technology. Bogor Agricultural Institute, Bogor.

Stevenson R.J. 2012. The role of attention in flavor perception. Flavour Biomed Cdentral. Depertment of Psychology, Macquarie University, Sydney, NSW, 2109.

Yeboah-Odur, C., Johnson P-N.T., Dawson-Sakyi, E dan Budu, A. 2010. Effect of processing on the colorimetry and viscoelastic properties of cassava starch, flour and cassava-plantain fufu flour. International Food Journal 17: 699-709. 